\title{
Clean Cities Helps Fleets Go Green
}

From yellow school buses to red emergency vehicles, businesses, schools, and government agencies are "cleaning up" their fleets by participating in green fleet programs. Green fleet programs encourage the use of alternative fuels and vehicles and provide support and recognition for participating fleets-public or private. Ohio and Illinois have established successful green fleet programs in collaboration with Clean Cities coalitions.

\section{Various Shades of Green}

Many organizations run green fleet programs, including state and local governments, metropolitan planning organizations, and Clean Cities coalitions. Green fleet programs certify vehicle fleets based on environmental and fuel-use requirements. Every green fleet program is different and the program team creates its own certification and recognition system.

The Ohio Green Fleets program, run by the Clean Fuels Ohio coalition, judges fleets based on their success in reducing petroleum use and emissions of particulate matter, nitrogen oxides, volatile organic compounds, and carbon dioxide. As a participant, MedCorp converted $80 \%$ of its emergency medical-service vehicles to run on propane. The only fleet to earn Ohio Green Fleets' prestigious five-star rating, MedCorp also created a new division to distribute and install propaneconversion systems.

In contrast, the Illinois Green Fleets program, run by the Illinois Environmental Protection Agency (EPA) with assistance from the Chicago Area Clean Cities, recognizes fleets for using specific technologies, including alternative fuels, hybrid electric vehicles, and diesel emissions aftertreatment retrofits. As a participant, the Chicago Department of Fleet Management bought compressed natural gas and hybrid electric vehicles, outfitted refuse trucks with idle-reduction devices, and encouraged employees to ride bicycles rather than drive cars.
Although all green fleet programs share a common mission, as demonstrated by the unique programs in Ohio and Illinois, there are a variety of ways for fleets to go green.

\section{Creating a Green Fleet Program}

Identifying resources is the first step in creating a green fleet program. To start, Ohio Green Fleets received state funding totaling $\$ 110,500$ in grants, as well as a $\$ 20,000$ private grant and $\$ 22,000$ from 26 sponsors. In Illinois, the green fleet program serves as a promotional umbrella under which four Illinois EPA programs operate. The four programs, which include a clean diesel, a clean school bus, an idle-reduction, and an alternative fuel rebate program, are funded separately. Funds come to the state through vehicle registrations, supplemental environmental project (SEP) payments, and other grants. The Chicago Area Clean Cities coalition also assists by organizing recognition events and workshops for the Illinois EPA's Green Fleet programs.

After securing resources, the Ohio and Illinois programs established procedures based on previous programs and local input. They also held promotional workshops to explain the programs, their scoring systems, and grant information. To evaluate fleets, the program teams from Ohio and Illinois created

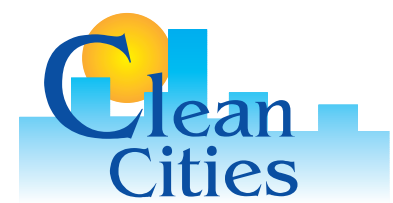

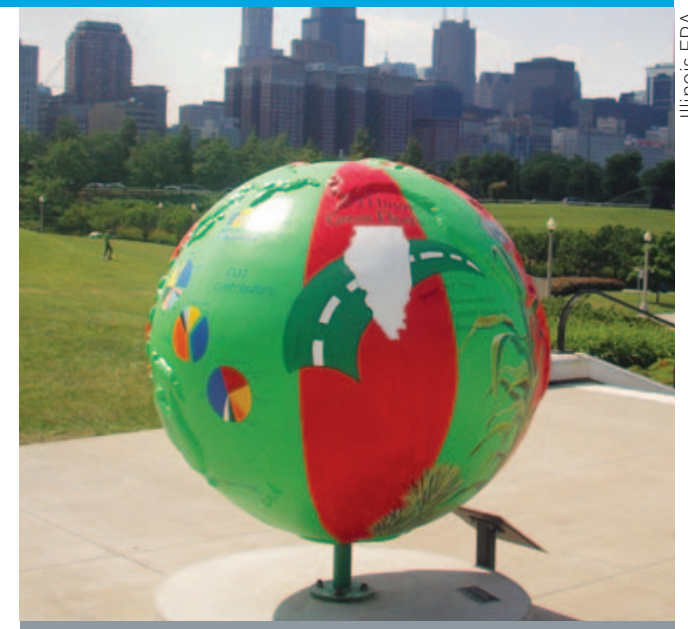

Part of a public art project designed to create environmental awareness, a "Cool Globe" prominently displays the Illinois Green Fleets' logo and mission. The globe provided a way to promote Illinois Green Fleets, one of the keys to a successful program.

and released application worksheets. ${ }^{1}$ The Illinois worksheet asks fleets about alternative fuel vehicles, use of alternative fuel infrastructure, volume of alternative fuel use, number of educational campaigns, and future commitments. The Ohio worksheet asks fleets for a detailed list of vehicles as well as annual mileage, idle time, retrofit/anti-idling technology, and amount and type of fuel used. The Ohio program adapted its worksheet from the U.S. EPA's Midwest Clean Diesel Initiative and uses the EPA's calculator to derive emissions and fuel savings.

After fleets apply, the program team evaluates if they qualify as green fleets. In Illinois, fleets must show substantial effort to use alternative fuels or advanced technology vehicles, which 88 fleets have done. Ohio's program assigns fleets points and star ratings depending on emissions and petroleum use relative to a baseline. In its first round of designations, with 12 applicants, Ohio announced three onestar fleets, one three-star fleet, and one five-star fleets.

See Illinois' worksheet at www.illinoisgreenfleets. org/survey and Ohio's enrollment form at wWw. ohiogreenfleets.org (click "Become a Member"). 


\section{Lessons Learned}

Green fleet programs have attracted media attention, drawn the praise of city and state governments, and increased stakeholder involvement. Program leaders in Ohio and Illinois learned some valuable lessons that can help others institute successful green fleet programs.

\section{Provide Good Public Relations}

Programs can improve public relations by designing a recognizable logo, providing information to the media, and assisting participants with outreach. Ohio Green Fleets issued a national press release and held an inaugural media event. Local and national media have recognized the Ohio and Illinois programs' participants. The Chicago mayor's office put an Illinois Green Fleets banner on City Hall and the Ohio Environmental Council promoted Ohio Green Fleets through its clean diesel initiative. This recognition built support for the program among participants and reinforced the message of reducing emissions and petroleum use.

For a city agency, green fleet certification can set an example and send a message to the community. "Running 180 vehicles on alternative fuels was not going to change the air quality of the entire Chicago area," says John Walton, fleet manager for the Forest Preserve District of DuPage

\section{For More Information}

Illinois Green Fleets

Darwin Burkhart, Illinois EPA

217-524-5008

darwin.burkhart@illinois.gov

www.illinoisgreenfleets.org

Ohio Green Fleets

Brad Couch, Clean Fuels Ohio

Brad@CleanFuelsOhio.org

www.ohiogreenfleets.org

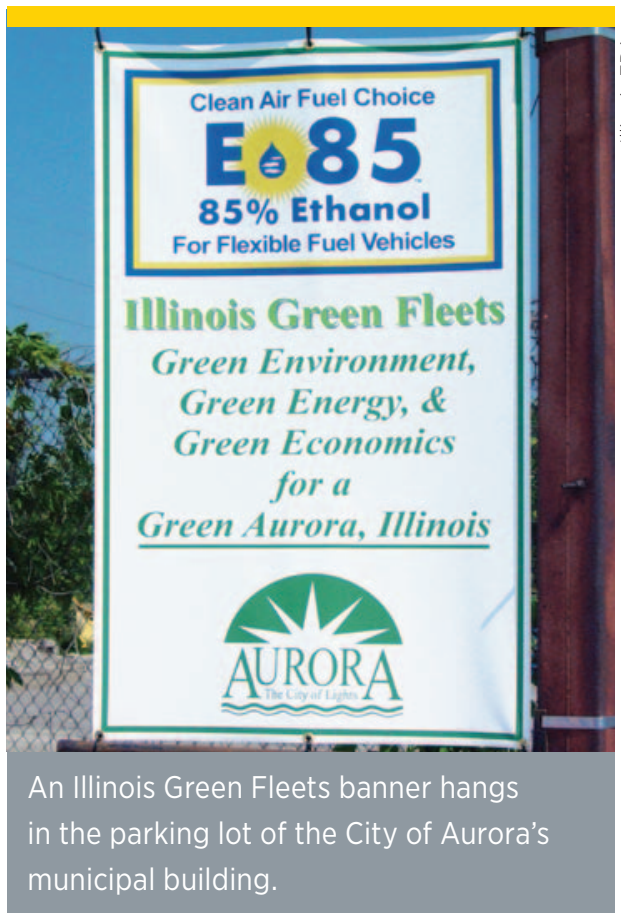

County, Illinois. "But us being a model of change could have an effect."

\section{Emphasize Technical Support}

Green fleets benefit from technical support received for their sustainability efforts.

Participants in the Ohio and Illinois programs said the programs help them adopt more alternative fuels and advanced technology vehicles by keeping them current on news and products. Through the program, fleet managers meet and learn from one another. Green fleet programs can provide support by providing frequent technology updates, networking opportunities, and additional information resources.

\section{Help with Grants}

For petroleum and emissions reduction strategies that require financial investment, green fleet programs can supply participants with grant information and application assistance. For example, the alternative fuel rebate program in Illinois provides rebates on purchases of E85
( $85 \%$ ethanol, $15 \%$ gasoline), B20 (20\% biodiesel, $80 \%$ petroleum diesel), natural gas, propane, electricity, and hydrogen, as long as the vehicle uses an alternative fuel for at least half the year. The program also offers rebates for alternative fuel vehicle purchases and conversions. The Illinois Green Fleets program helps participants take advantage of these incentives.

\section{Involve a Variety of Stakeholders}

Networking opportunities are not limited to fleet managers. Engaging a variety of stakeholders, including nonprofit organizations, local planning organizations, state and national agencies, and industry groups, strengthens a program. These groups provide new contacts, logistical and financial support for workshops, and technical expertise. In particular, state and national EPA representatives can connect participants with funding opportunities such as Supplemental Environmental Project grants. ${ }^{1}$

\section{Build on Voluntary Efforts}

Programs can use the achievements of a voluntary program to prove the potential to a city government by using the program's tools - such as the application worksheet and grant information-to help city fleet managers carry out policy. Concurrent with its voluntary green fleet program, Clean Fuels Ohio worked with the Columbus, Ohio, government to establish a city green fleet policy, which requires drivers to complete an "ecodriving" course, fits diesel vehicles with anti-idling technology, and fuels diesel equipment with a biodiesel blend.

\footnotetext{
A Supplemental Environmental Project is part of an environmental enforcement settlement under the terms of which a violator agrees to undertake an environmentally beneficial project in exchange for a reduced penalty. See www.epa-echo.gov/ echo/about_sep.htm/for more information.
}

For additional information, please contact: EERE Information Center 1-877-EERE-INF (1-877-337-3463) www.eere.energy.gov/informationcenter

DOE/GO-102009-2852 • August 2009
Prepared by the National Renewable Energy Laboratory (NREL), a national laboratory of the U.S. Department of Energy, Office of Energy Efficiency and Renewable Energy; NREL is operated by the Alliance for Sustainable Energy, LLC. Printed with a renewable-source ink on paper containing at least $50 \%$ wastepaper, including $10 \%$ post consumer waste. 